\title{
CORRELATIONS BETWEEN CONTEMPORARY METHODS IN THE DIAGNOSIS OF CHLAMYDIA TRACHOMATIS UROGENITAL INFECTIONS
}

\author{
Ilko Bakardzhiev ${ }^{1}$, George Pehlivanov², E. Kovachev ${ }^{3}$ \\ 1) Medical College, Medical University of Varna, Bulgaria \\ 2) Department of Dermatology and Venereology, \\ Medical University of Sofia, Bulgaria \\ 3) Department of Obstetrics and Gynecology, \\ Medical University of Varna, Bulgaria
}

\begin{abstract}
The subject of this study were 486 outpatients between the ages of 17 and 62, diagnosed with urethritis, epidydimitis, prostatitis, cervicitis, endocervicitis, pelvic inflammatory disease and sterility. The following tests were used to make the diagnosis of Chlamydia trachomatis: Enzyme Immunoassay (EIA), Enzyme-Linked Fluorescent Assay (ELFA), Polymerase Chain Reaction DNA amplification for Chlamydia Trachomatis, Neisseria Gonorrhoeae, Mycoplasma Genitalium and Ureaplasma Urealyiticum. Comparison PCR and EIA showed statistically significant difference between the positive results obtained by the two methods $(p<0,001)$. Comparing PCR and ELFA on the other hand, did not show any statistically significant difference $(p>0,1)$. EIA is a method that gives a higher percentage of nonspecific positive reactions, while the results obtained from ELFA are much closer to the ones obtained by PCR. According to contemporary evidence based medicine, the developmet of unified standard methods for diagnosis and evaluation is of vital importance, not only for the patient and the treating physician but also concerns for the healthcare system, the general public and the pharmaceutical companies as well.
\end{abstract}

Key words: Chlamydia Trachomatis, EIA, ELFA, PCR

\section{INTRODUCTION}

Chlamydia Trachomatis with its various serotypes A-C, D-K, L1-L3 is an etiologic factor for a wide group of diseases: urethritis, epididimitis, cervicitis, salpingitis, endometritis, conjunctivitis, keratitis, Reiter syndrome, Lymphogranuloma Venereum, Pelvic Inflammatory Disease and Neonatal pneumonia[3]. Chlamydiae are obligate intracellular bacteria that grow in eukaryotic cells and have a unique biphasic life cycle. Chlamydia trachomatis(CT) serotypes D-K have an affinity for the cylindrical epithelium of the mucous membranes where they grow and multiply. They are responsible for two types of intracellular inclusions
- elementary and reticular bodies. The extracellular elementary bodies enter the host cell by receptor- mediated endocythosis and transform into reticular cells, capable of multiplication. Chlamydiae have their own metabolic system but they are not capable of synthesizing adenosine triphosphate (ATP) so they use the one synthesized by the host cell. Infection with chlamydia organisms invokes a humoral immune response, resulting in secretory immunoglobulin $\mathrm{A}(\mathrm{Ig} \mathrm{A})$ and circulatory immunoglobulin $\mathrm{M}$ ( $\operatorname{Ig} \mathrm{M})$ and immunoglobulin $\mathrm{G}(\operatorname{Ig} \mathrm{G})$ antibodies and a cellular immune response[2]. The lipopolysaccharide antigen of Chlamydia trachomatis is identical for all gram-negative and some gram-positive bacteria. The existing tests for detecting antibodies against this antigen are with limited specificity for the diagnosis of Chlamydia urogenital infections. Over the last 15 years we have seen an increasingly widespred use of serologic tests in Bulgaria wich has led to the over- diagnosis of Chlamydia urogenital infections.

\section{OBJECTIVE}

The main objective of this study is to explore the correlations between the existing methods for diagnosis of Chlamydia urogenital infections.

\section{MATERIALS AND METHODS}

The subject of this study were 486 outpatients between the ages of 17 and 62, diagnosed with urethritis, epidydimitis, prostatitis, cervicitis, endocervicitis, pelvic inflammatory disease and sterility. All these patients have been seen at the following sites: the Clinic of Dermatology and Venereology of Alexandrosvka University Hospital in Sofia, the outpatient dermatology office at Resort Policlinic in Varna and the Medical Centre for Assisted Reproduction" Varna". The following tests were used to make the diagnosis of Chlamydia trachomatis: Enzyme Immunoassay (EIA), Enzyme-Linked Fluorescent Assay (ELFA), Polymerase Chain Reaction DNA amplification for Chlamydia 
Trachomatis, Neisseria Gonorrhoeae, Mycoplasma Genitalium and Ureaplasma Urealyiticum $[11,12,13]$. Enzyme Immunoassay (EIA): To diagnose the Chlamydia antibodies we have used ImmunoComb Chlamydia trachomatis (Orgenics), which is a fast quantitative test for detection of antibodies against Chlamydia Trachomatis in human serum or plasma. The method relies on indirect enzyme immunoassay. Enzyme-Linked Fluorescent Assay (ELFA): Despite the fact that cell culture is still considered to be the gold standard for making the diagnosis of Chlamydia infection, the techniques based on detection of antigens are much easier to perform and they are used in a larger group of clinical laboratories[6]. The qualitative test for Chlamydia antigen detection is using ELFA technique (Enzyme-Linked Fluorescent Assay). We have used one by VIDAS (Vidas Chlamydia CHL) bio Merieux for urethral and cervical samples. This method is based on immunoanalysis followed by fluorescent detection. Polymerase Chain Reaction DNA amplification: The idea behind this method is detection and multiplication of a specific part of the DNA of the microorganism. Even minimal quantities of the pathogen are sufficient for determining the cause of the infection. We have used the following DNA amplification tests: Amplicor, Chlamydia Trachomatis; Neisseria Gonorrhoeae HoffmannLa Roche and Sacace Biotechnologies(Chlamydia Trachomatis, Neisseria Gonorrhoeae and Ureaplasma Urealyticum). The test involves three stages: DNA extraction, amplification and detection. The first morning urine is collected from patients with urethritis, prostate secretion and cells from the cervix[4,5,10]. All samples are collected, stored and processed according to the instructions. We followed the guidelines in interpreting the test results. The samples with extinction more than 0.8 for Chlamydia Trachomatis were considered positive, while for Neisseria Gonorrhoeae this value was more than 0.2 (Amplicor). Borderline test results were repeated. If the test result was not convincing, a new sample was taken. Statistical analysis was performed with Windows EXCEL and SPSS.

\section{RESULTS}

Analysis of the obtained data shows the following distribution of antichlamydia antibodies: Ig A 39\% ( $n=189)$, Ig M $35 \%(n=170)$, Ig G 60\% ( $n=292)$. Comparison of the history of infection shows that antichlamydia antibodies are found in cases with long term history, while Ig M antibodies in more recent ones. In order to compare the results of 182 subjects positive for $E I A$ we also tested the same group with an Enzyme- Linked Fluorescent Assay (ELFA). Only $15 \%$ $(\mathrm{n}=27)$ were positive for both EIA and ELFA, which proves the lack of specificity of the EIA antichlamydia test. In order to increase the sensitivity and specificity of the results for Chlamydia Trachomatis in 91 subjects, we performed a $P C R$ test by micro hybridization technique. Only $9,2 \%$ of those tested were positive for Chlamydia. Comparing $P C R$ and $E I A$ showed statistically significant difference between the positive results obtained by the two methods $(\mathrm{p}<0,001)$. On the other hand, comparing PCR and ELFA, did not show any statistically significant difference $(\mathrm{p}>0,1)$. EIA is a method that gives a higher percentage of nonspecific positive reactions, while the results obtained from ELFA are much closer to the ones obtained by $P C R$. A representative group of 123 subjects was tested simultaneously with microbiologic culture growth and serologic tests, as well as PCR. The results for Bacteria, Mycoplasma, Trichomonas and Chlamydia were as follows: Mixed $36 \%$, Mycoplasma $32 \%$, Bacteria $19 \%$, Chlamydia trachomatis 9\%, Neisseria Gonorrhoeae 7 \%, Candida 6\%, and Trichomonas Vaginalis $5 \%$. The mixed infections comprised of Bacteria, Mycoplasma and Chlamydia trachomatis. The most frequent bacteria were Staphylococcus Aureus, followed by Enterecoccus and Escherichia Coli. The most frequent Mycolplasma was M. Hominis.

\section{DISCUSSION}

Serologic test for Chlamydia Trachomatis is not the most reliable method for establishing the diagnosis. During the course of the infection with $\mathrm{CT}$, a different kind of antibodies appears, similar to the immunological course of other infectious diseases. Ig M antichlamydia antibodies appear first and usually disappear after 30-45 days. Their presence is indicative of an acute or an exacerbated chronic infection. They are not found in asymptomatic carriers. IgA antichlamydia antibodies are also present in acute infection and are a better marker but they are present in only about $40 \%$ of the cases. It must also acknowledged that $\operatorname{IgA}$ is locally produced. Antibodies from the IgG class appear two months after the beginning of the infection and they can persist with a different titter for months, even years, after the acute infection is no longer active. The presence of $\operatorname{IgG}$ antichlamydia antibodies therefore cannot be the single most important criteria for establishing the diagnosis and evaluation of the treatment response. There are other tests which detect the lipopolysaccharide antigen of Chlamydia trachomatis (mainly PCK and ELISA). This antigen is specific not only for Chlamydia trachomatis, but also for all Gram-negative bacteria. This test is valuable only for determining the presence of an Ornithosis/Psittacosis infection and it is positive with other Gram-negative bacteria. Regrettably, we observe a trend that this serologic test for Chlamydia is widely used in Bulgaria, contrary to the accepted international practice, which is to use it only as an additional test and not as a main diagnostic tool. Some authors consider the presence of IgA and high titers of IgG as an indicator of an acute infection but the majority consider it of little diagnostic value[8]. High titters of serum antibodies may be indicative of an acute infection but the do not always correlate with the presence of Chlamydia 
Trachomatis. One extensive study conducted by E. Petrova and B. Dimitrov (1994) showed that if diagnosis and treatment are based on the serologic tests alone, a large group of patients will not be treated adequately, another group will be treated unnecessarily or for too long [7]. It is also generally considered that the reduction of the IgG titter around the third month and its complete disappearance is an indicator for the effectiveness of the antibiotic therapy. The results from the three tests for Chlamydia trachomatis that we have used (EIA, ELFA, PCR) show that EIA has the highest percentage of nonspecific positive results, while the results from ELFA are closer to the ones obtained with PCR. The evaluation of each test comprises of the following criteria: validity, reproducibility, sensitivity and accessibility.The clinical picture correlates with the results obtained with PCR, unlike the serologic tests EIA and ELFA, which determines that PCR is the most reliable test for monitoring the causative agent, activity and therapeutic effect of the treatment[1].

\section{CONCLUSION}

The results from different authors for the causative agents are not easily comparable due to the difference in the methods used, their modifications and the scale of the representative groups. The frequent monitoring of the different types of chlamydia urogenital infections and their activity is based on the clinical diagnosis, so called symptomatic approach or older diagnostic methods. According to contemporary evidence based medicine, the need for unified standard methods for diagnosis and evaluation is of vital importance and not only for the patient and the treating physician but also concerns for the healthcare system, the general public and the pharmaceutical companies. The most reliable modern method $(P C R)$ can be a substantial economic burden for the patients and their relatives due to the specifics of the healthcare system in this country and the equipment available in the diagnostic laboratories.

\section{REFERENCES:}

1. Anagrius C, Lore B, Jensen JS. Mycoplasma genitalium: prevalence, clinical significance, and transmission. Sex Transm Infect. 2005 Dec;81(6):458-62. doi:10.1136/ sti.2004.012062 CrossRef] [PubMed]

2. Black, C.M. Current methods of laboratory diagnosis of Clamydia trachomatis infections. Clin. Microbiol. Rev. 1997 Jan;10(1):160-184. [PubMed]

3. Mitchell, S. A., S. R. Shukla, R. N. Thin. Aetiology of non-gonococcal urethritis: A possible relation to other infections. Int. J. STD \& AIDS. 1990 Nov;1(6):429-431. [PubMed]

4. Modarress KJ, Cullen AP, Jaffurs WJ Sr, Troutman GL, Mousavi N, Hubbard RA, et al. Detection of Chlamydia trachomatis and Neisseria gonorrhoeae in swab specimens by the Hybrid Capture II and PACE 2 nucleic acid probe tests.- Sex. Transm. Dis. 1999 May;26(5):303-308. [PubMed]

5. Moncada, J., J. Schachter, G. Bolan, Engelman J, Howard L, Mushahwar I, et al. Confirmatory assay increases specificity of the Chlamydiazyme test for Chlamydia trachomatis infection of the cervix.- J. Clin.
Microbiol., 1990 Aug;28(8):1770-1773. [PubMed]

6. Ouzounova V, J. Haralambieva, J. Jankov, D. Petrov, I. Mitov. Prevalence of Chlamydia Trachomatis infections in symptomatic patients in Bulgaria. Journal of IMAB, 2004 10(1):11-14. DOI: 10.5272/ jimab.2004101.11 CrossRef]

7. Petrova E., B. Dimitrov. Serological monitoring of patients with sexually transmitted chlamydia infections. Dermatol. and Venereol. Bulg. 1994, No 2-3, 20-23

8. Rabenau, H. F., E. Kohler, M. Peters, H. W. Doerr, B. Weber. Low correlation of serology with detection of Chlamydia trachomatis by ligase chain reaction and antigen EIA. Infection. 2000 MarApr;28(2):97-102. doi:10.1007/ s150100050054 CrossRef] [PubMed]

9. Tchoudomirova K, Nuhov P, Tchapanova A. Prevalence, epidemiological and clinical correlates of genital Chlamydia trachomatis infection. J Eur Acad Dermatol Venereol. 1998 Nov;11(3):214-20. [PubMed]

10. Tchoudomirova, K., A. Tchapanova, F. Nouchov. Detection of Chlamydia trachomatis in first-void urine from men and women as an alternative to swabs. Folia Med (Plovdiv), 39, 1997, No 4, 30-36. [PubMed]

11. Thejls, H., J. Gnarpe, H. Gnarpe, P. G. Larsson, J. J. Platz-Christensen, L. Ostergaard, A. Victor. Expanded gold standard in the diagnosis of Chlamydia trachomatis in a low prevalence population: diagnostic efficacy of tissue culture, direct immunofluorescence, enzyme immunoassay, PCR and serology. Genitourin. Med., 70, 1994, No 5, 300-303.

12. Van Dyck E, Ieven M, Pattyn S, Van Damme L, Laga M. Detection of Chlamydia trachomatis and Neisseria gonorrhoeae by enzyme immunoassay, culture, and three nucleic acid amplification tests. J. Clin. Microbiol. 2001 May;39(5):1751-1756. doi:10.1128/JCM.39.5.1751-1756.2001 CrossRef] [PubMed]

13. Verkooyen RP, Peeters MF, van Rijsoort-Vos JH, van der Meijden WI, Mouton JW. Sensitivity and specificity of three new commercially available Chlamydia trachomatis tests.- Int. J. STD AIDS. 2002 Dec;13 Suppl. 2:23-25. doi: 10.1258/ 095646202762226119 CrossRef] [PubMed]

\author{
Address for correspondence: \\ Ilko Bakardzhiev, MD, Ph D \\ Medical College, Medical University of Varna \\ 84, Tzar Osvoboditel str., Varna, Bu;garia \\ e-mail:varna2008@gmail.com
}

